\title{
Responses to Root-zone Water Content of Shrub Congeners from Eastern North America and Mediterranean California
}

\author{
Bryan J. Peterson and William R. Graves ${ }^{1}$ \\ Department of Horticulture, Iowa State University, 106 Horticulture Hall, \\ Ames, IA 50011-1100
}

Additional index words. Sambucus, Ptelea, elderberry, hop tree, wafer ash, drought, flooding, intraspecific and interspecific variation, biomass allocation, native landscape plants

\begin{abstract}
Numerous genera of plants are distributed in both eastern North America and in portions of California with the dry summers of Mediterranean climates. We compared effects of flooding and drought on relative growth rate (RGR), photosynthesis, and biomass of seedlings of two genera, Sambucus L. and Ptelea $L$., with congeners in both regions. Ptelea crenulata Greene and Sambucus nigra ssp. cerulea (Raf.) R. Bolli from the San Francisco Bay area and Ptelea trifoliata L. and Sambucus nigra ssp. canadensis (L.) R. Bolli from mesic, deciduous forests in eastern North America were studied. Potted seedlings were subjected to six treatments, three extents of root-zone inundation and three severities of drought (irrigation when soil moisture by volume decreased to $5 \%$, $10 \%$, and $20 \%$ ). After 5 weeks, deleterious effects of inundation were more pronounced among plants from the West than among their eastern congeners. For example, RGR of western and eastern Sambucus with completely inundated root zones was reduced $116 \%$ and $25 \%$, respectively. All western and eastern Ptelea died when root zones were completely inundated, but inundating the lower half of the root zone killed all western plants but only reduced RGR among eastern plants. Photosynthesis of Sambucus from the West was lowest with complete inundation and was similar across the remaining treatments. In contrast, photosynthesis of eastern Sambucus was lowest during severe drought but otherwise similar. Photosynthesis of Ptelea was sensitive to both drought and flooding, and moderate root-zone water content led to the highest rates for both western and eastern plants. For both genera, maximal photosynthesis per unit leaf area was greater among western than eastern plants, but eastern plants had greater total leaf area and biomass. Root-to-shoot ratios of western Sambucus were greater than ratios of plants from the East after all treatments, whereas western Ptelea had greater root-to-shoot ratios than eastern Ptelea only under severe drought. Although comparative sensitivity to drought of plants from California and eastern North America varied in these genera, Mediterranean Sambucus and Ptelea both showed greater sensitivity to root-zone inundation than did their eastern congeners.
\end{abstract}

Numerous woody genera are distributed in both eastern North America and in portions of California with the dry summers of Mediterranean climates. Such genera may harbor substantial variation among congeners in response to soil water content. During drought, taxa from seasonally xeric habitats may maintain greater photosynthetic rates, allocate proportionally more photosynthates to root foraging, and survive at greater frequencies than their mesic counterparts (Abrams, 1990; Abrams et al., 1990; Baraloto et al., 2007; Chunyang et al., 2000; Kubiske and Abrams, 1992). Conversely, taxa restricted in

Received for publication 19 Nov. 2012. Accepted for publication 5 Mar. 2013

We thank Kevin Duerfeldt, Katey Warnberg, Pete Veilleux, Gregg Weber, Beth Shimp, Nadine Nedza, and the staff of the Vienna Ranger Station of the Shawnee National Forest for helpful assistance.

${ }^{1}$ To whom reprint requests should be addressed; e-mail graves@iastate.edu. nature to mesic or seasonally flooded habitats may perform better after being planted at sites prone to flooding because of their capacities to maintain greater photosynthetic rates and to resist physiological stress in hypoxic soils (Baraloto et al., 2007; Keeley, 1979). Knowledge of variation in photosynthetic capacity, growth rate, and biomass accrual between congeners in Mediterranean California and the comparatively mesic eastern United States could enhance our ability to select the most suitable taxa for specific soilmoisture conditions in managed landscapes.

Shrubs and trees in the genera Sambucus and Ptelea are valued in horticultural landscapes. Members of the genus Sambucus produce showy clusters of white flowers followed by attractive fruits that attract wildlife and can be used for jellies and wines, whereas trees of Ptelea are shade-tolerant and display unusual fruits (Dirr, 1998). Congeners of Sambucus and Ptelea exist in eastern North America and in portions of California characterized by the dry summers of Mediterranean climates. Because of morphological diversity across their distributions, taxonomic confusion persists within both genera, and various species and subspecies have been designated (Bailey, 1962; Bolli, 1994; Eriksson and Donoghue, 1997; Greene, 1906). Sambucus nigra ssp. canadensis (syn: $S$. canadensis L.) grows in damp, rich soils in much of eastern North America (Dirr, 1998), whereas Sambucus nigra ssp. cerulea (syns: S. cerulea Raf., S. mexicana Presl.) in the San Francisco Bay area grows in habitats ranging from upper riparian terraces to seasonally dry elderberry savannahs and chaparrals (Ackerly et al., 2002; Koch-Munz and Holyoak, 2008). Ptelea trifoliata inhabits moist understories in eastern North America (Dirr, 1998), whereas Ptelea crenulata grows in dry chaparrals and woodlands in California, where it is endemic (Corelli, 2005). For simplicity, we will refer to these taxa as eastern and western congeners

The Mediterranean mesoclimate near the San Francisco Bay is characterized by an average annual precipitation of 25 to $75 \mathrm{~cm}$, whereas the region from which we obtained germplasm of the eastern congeners (southern Wisconsin and southern Illinois for Ptelea and Sambucus, respectively) averages 80 to $120 \mathrm{~cm}$ of precipitation annually [Changnon, 2003; National Climatic Data Center (NCDC), 2012]. Temporal distribution of precipitation differs also. Habitats supporting the western congeners receive $\approx 1 \mathrm{~cm}$ of precipitation from June through September, whereas 30 to $40 \mathrm{~cm}$ of rain is typical during those 4 months where we collected germplasm farther east (NCDC, 2012). Such seasonality of precipitation may correspond to droughtadaptive characteristics of closely related woody taxa (Chunyang et al., 2000). The presence of congeners in these divergent habitats could be viewed as evidence for physiological divergence between the species, but the natural distributions of taxa are not necessarily predictive of their capacities to withstand stressors (Parolin et al., 2010; Schrader et al., 2005; Stewart et al., 2007) Therefore, we questioned whether the differences in precipitation in the habitats of the western and eastern congeners of the species of Sambucus and Ptelea we studied are predictive of their responses to dry and inundated root zones. Several traits suggest that eastern and western congeners of these genera have evolved to possess different degrees of drought resistance. Although the eastern congener of both genera has glabrous or nearly glabrous leaves, the western congener of Sambucus is pubescent on both the abaxial and adaxial foliar surfaces, and the western congener of Ptelea has adaxial pubescence (Corelli, 2005; Dirr, 1998). The western congener of Ptelea also has smaller leaves than its eastern counterpart. We tested the hypothesis that deleterious effects of inundation and drought are more pronounced among plants from western and eastern North America, respectively, compared with their congeners by measuring RGR, photosynthesis, and 
biomass accrual in response to different irrigation treatments in a common environment.

\section{Materials and Methods}

Fruits were collected from eastern and western congeners of Sambucus and Ptelea in Sept. 2009. Fruits of the western congener of Ptelea were collected in Contra Costa County, CA, from plants on a hilltop and absent of green leaves, consistent with droughtinduced dormancy. Fruits of the western congener of Sambucus were collected in Alameda County, CA, from plants with green leaves in a dry ravine within a landscape characterized by undulating topography. The eastern congeners of Ptelea and Sambucus were collected from mesic forests in Dodge County, WI, and Johnson County, IL, respectively. Seeds were warm- and cold-stratified and germinated in the spring of 2010. Seedlings were transplanted singly into plastic pots with heights of $14.6 \mathrm{~cm}$ and top diameters of $15.2 \mathrm{~cm}$ that were filled with a soilless, peatmoss-based medium (Fafard ${ }^{\circledR}$ 52; Fafard, Inc., Agawam, MA). Seedlings of Sambucus were randomly assigned to one of six treatments of root-zone moisture when they were $\approx 3$ months old and lengths of longest shoots were between 15 and $20 \mathrm{~cm}$. Seedlings of the slower-growing Ptelea spp. were cultured with moist root zones for the growing season of 2010, held over winter in a minimally heated greenhouse, and subjected to treatments after resumption of growth in 2011, when shoots were 10 to $15 \mathrm{~cm}$ long.

The same six treatments were imposed during both experiments. Plants in three treatments were irrigated to container capacity with tap water when root zones were $5 \%$, $10 \%$, or $20 \%$ moisture by volume. Plants in the other three treatments were continuously inundated, either throughout the entire root zone or only in the lowest 7.5 or $3.5 \mathrm{~cm}$, by placing growing containers into saucers of water. Root-zone moistures were measured by inserting an HH1 Theta Meter (Delta-T Devices, Cambridge, U.K.) probe into the substrate from above to determine whether irrigation was necessary. A completely randomized design was used for both experiments, with five (Sambucus) or four (Ptelea) replicate plants of each congener per treatment. Decisions to irrigate based on root-zone moisture were made for individual replicates rather than on means of replicates within treatments. Following this approach, plants irrigated at predetermined thresholds of rootzone moisture were subjected to as many as nine dry-down cycles when irrigated at $20 \%$ root-zone moisture to as few as three or four dry-down cycles when irrigated at 5\% rootzone moisture. Experiments were conducted in a glass-glazed greenhouse in Ames, IA, with natural daylengths beginning 11 June (Sambucus) and 8 July (Ptelea). Sambucus were subjected to a mean photosynthetically active radiation $(P A R)$ at solar noon of $630 \mu \mathrm{mol} \cdot \mathrm{m}^{-2} \cdot \mathrm{s}^{-1}(\mathrm{SE}=42)$, and mean, minimum, and maximum daily temperatures were
24, 16, and $36^{\circ} \mathrm{C}$, respectively. For Ptelea, $P A R$ at solar noon averaged $508 \mu \mathrm{mol} \cdot \mathrm{m}^{-2} \cdot \mathrm{s}^{-1}$ $(\mathrm{SE}=22)$, and mean, minimum, and maximum temperatures were 27,24 , and $32{ }^{\circ} \mathrm{C}$, respectively. An AccuPAR LP-80 Ceptometer (Decagon Devices, Inc., Pullman, WA) was used to record $P A R$ on three dates during each experiment.

Thirty-five days (Sambucus) or $38 \mathrm{~d}$ (Ptelea) after initiation of treatments, photosynthesis was measured on the youngest fully expanded leaf of each plant by using a LI-6400 photosynthesis system (LI-COR, Inc., Lincoln, NE) equipped with a reference $\mathrm{CO}_{2}$ of $400 \mu \mathrm{L} \cdot \mathrm{L}^{-1}$ and a red-blue lamp providing $1000 \mu \mathrm{mol} \cdot \mathrm{m}^{-2} \cdot \mathrm{s}^{-1} P A R$. Leaf temperature during measurements ranged from 25 to $33{ }^{\circ} \mathrm{C}$. To determine the relationship between root-zone moisture and photosynthesis, root-zone moisture was measured immediately before photosynthesis by using an $\mathrm{HH} 1$ Theta Meter.

After photosynthesis was recorded, plants were harvested and surface area of leaves was measured with a LI-COR 3100 leaf area meter (LI-COR, Inc.), and roots and shoots (stems + leaves) were dried in a $69^{\circ} \mathrm{C}$ oven for more than $3 \mathrm{~d}$ and weighed. The formula of $($ whole-plant RGR $)=\ln ($ final dry weight $)$ $\ln$ (initial dry weight)/(number of days) was used. Initial weights for each taxon were determined by harvesting five (Sambucus) or four (Ptelea) additional, randomly chosen plants of each congener when treatments were initiated. All data were analyzed with the Statistical Analysis System 9.1.3 (SAS
Institute Inc., Cary, NC) and Fisher's least significant difference test.

\section{Results}

Sambucus. Inundation of root zones decreased whole-plant RGR and/or survival of plants of western and eastern congeners of each genus (Fig. 1). Compared with the most favorable treatments, complete inundation of root zones reduced the RGR of the western and eastern congener of Sambucus by $116 \%$ and $25 \%$, respectively. The marked reduction in RGR among western Sambucus with completely inundated root zones was the result of the death of most roots and shoots within $5 \mathrm{~d}$ of treatment initiation followed by a slow recovery as stems formed adventitious roots near the surface of the medium. Drying of root zones to $5 \%$ moisture by volume reduced the RGR of the western and eastern Sambucus by $42 \%$ and $28 \%$, respectively.

Photosynthesis of Sambucus differed markedly between congeners in response to drought and inundation, and the western congener had greater rates of photosynthesis under various treatment conditions (Fig. 2). Photosynthesis of the western congener of Sambucus was lowest with complete inundation $\left(4 \mu \mathrm{m} \cdot \mathrm{m}^{-2} \cdot \mathrm{s}^{-1}\right)$ but was otherwise similar across remaining root-zone conditions $\left(11 \mu \mathrm{m} \cdot \mathrm{m}^{-2} \cdot \mathrm{s}^{-1}\right)$, whereas photosynthesis of the eastern congener was lowest under severe drought $\left(1 \mu \mathrm{m} \cdot \mathrm{m}^{-2} \cdot \mathrm{s}^{-1}\right)$ but otherwise was 4 to $6 \mu \mathrm{m} \cdot \mathrm{m}^{-2} \cdot \mathrm{s}^{-1}$.

Measures of biomass showed that both congeners of Sambucus were sensitive to

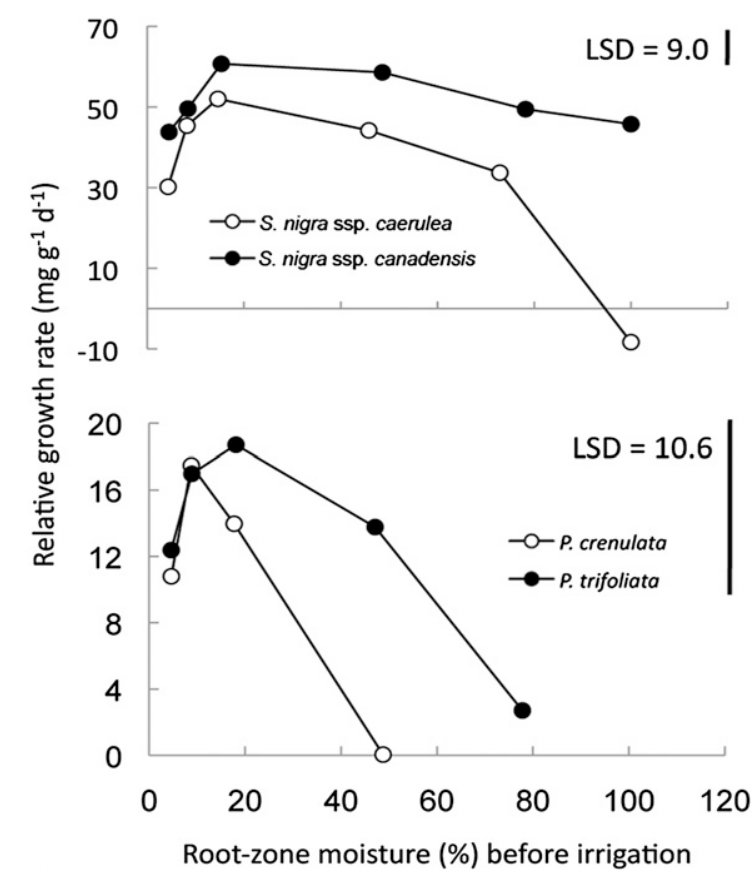

Fig. 1. Relative growth rate of seedlings of Sambucus and Ptelea grown for 35 and $38 \mathrm{~d}$, respectively, under six conditions of root-zone moisture. Each circle represents the mean root-zone moisture at the time of irrigation and the mean response of five (Sambucus) or four plants (Ptelea). Within taxa, each symbol represents, from left to right, plants irrigated when root zones dried to $5 \%$ moisture by volume to plants with root zones completely inundated (Sambucus) or plants with root zones shallowly inundated $(P$. crenulata $)$ or moderately inundated $(P$. trifoliata). Treatments in which all plants of a taxon died are not represented. 
drought and inundation and that moderate root-zone moistures fostered maximal root and shoot dry weights and leaf areas (Fig. 3). Root-to-shoot ratios were greatest when rootzone moistures were moderate to dry. Across treatment groups, plants of the eastern congener of Sambucus often produced root and shoot biomass and leaf area equal to or exceeding that of their western counterparts (Fig. 3), whereas root-to-shoot ratios of eastern congeners never exceeded those of western congeners.

Ptelea. All plants of Ptelea died when root zones were fully inundated, whereas

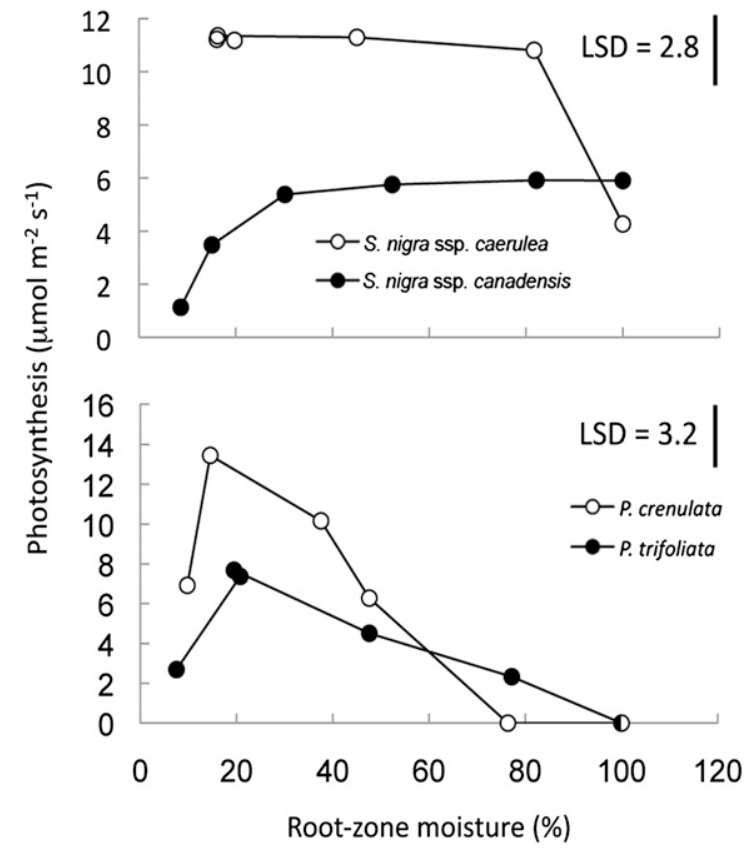

Fig. 2. Photosynthesis of seedlings of Sambucus and Ptelea grown for 35 and 38 d, respectively, under six conditions of root-zone moisture. Each circle represents the mean root-zone moisture at the time of measurement and the mean response of five plants (Sambucus) or four plants (Ptelea). Within taxa, each symbol represents, from left to right, plants irrigated when root zones dried to $5 \%$ moisture by volume to plants with root zones completely inundated. For Ptelea, photosynthesis rates of zero are displayed when all plants of a taxon died from an inundation treatment. In some cases, the average rootzone moisture of plants in a more severe drought treatment group was greater than that of plants in a less severe drought treatment group at the time of measurement.

moderate inundation killed all plants of the western congener and reduced RGR of plants of the eastern congener by $85 \%$ (Fig. 1). Drying root zones did not decrease RGR of either congener (Fig. 1).

Photosynthesis of Ptelea was similar between congeners in response to drought and inundation; dry and saturated root zones diminished the rate of photosynthesis, and both western and eastern plants had the greatest rate of photosynthesis $\left(14 \mu \mathrm{m} \cdot \mathrm{m}^{-2} \cdot \mathrm{s}^{-1}\right.$ and 4 to $8 \mu \mathrm{m} \cdot \mathrm{m}^{-2} \cdot \mathrm{s}^{-1}$, respectively) under moderate root-zone moistures (Fig. 2). Plants from the West maintained greater rates of photosynthesis per unit leaf area under severe drought than did plants of the eastern congener.

Measures of biomass showed that both congeners of Ptelea were sensitive to drought and inundation and that moderate root-zone moistures fostered maximal root and shoot dry weights and leaf areas (Fig. 4). Root-toshoot ratios were greatest when root-zone moistures were moderate to dry. Across treatment groups, plants of the eastern congener of Ptelea consistently produced root and shoot biomass and leaf area equal to or exceeding that of their western counterparts (Fig. 4), whereas plants of the western congener had root-to-shoot ratios greater than those of their eastern counterparts when root zones were allowed to dry.

\section{Discussion}

Consistent with their presence in the Mediterranean climate of the San Francisco Bay area, plants of Sambucus nigra ssp. cerulea and Ptelea crenulata were less tolerant of flooding than their eastern counterparts, Sambucus nigra ssp. canadensis and Ptelea trifoliata (Figs. 1 to 4). Previous work with Sambucus nigra ssp. cerulea demonstrated
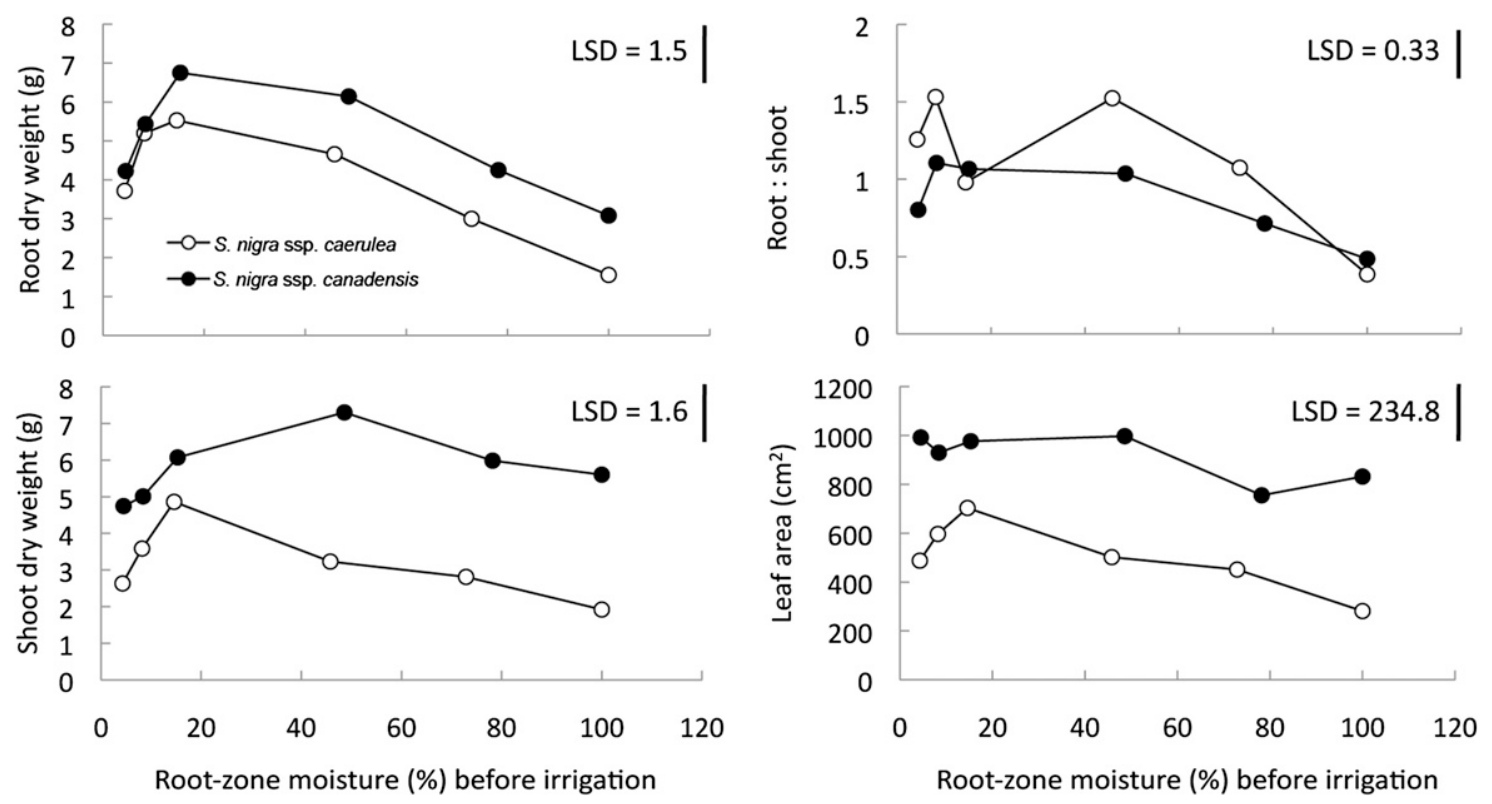

Fig. 3. Root dry weight, shoot dry weight, root:shoot, and total leaf area of seedlings of Sambucus grown for 35 d in each of six root-zone moisture conditions. Each circle represents the mean root-zone moisture at the time of irrigation and the mean response of five plants to treatments ranging from irrigation at $5 \%$ root-zone moisture by volume (left terminal) to complete inundation (right terminal). 

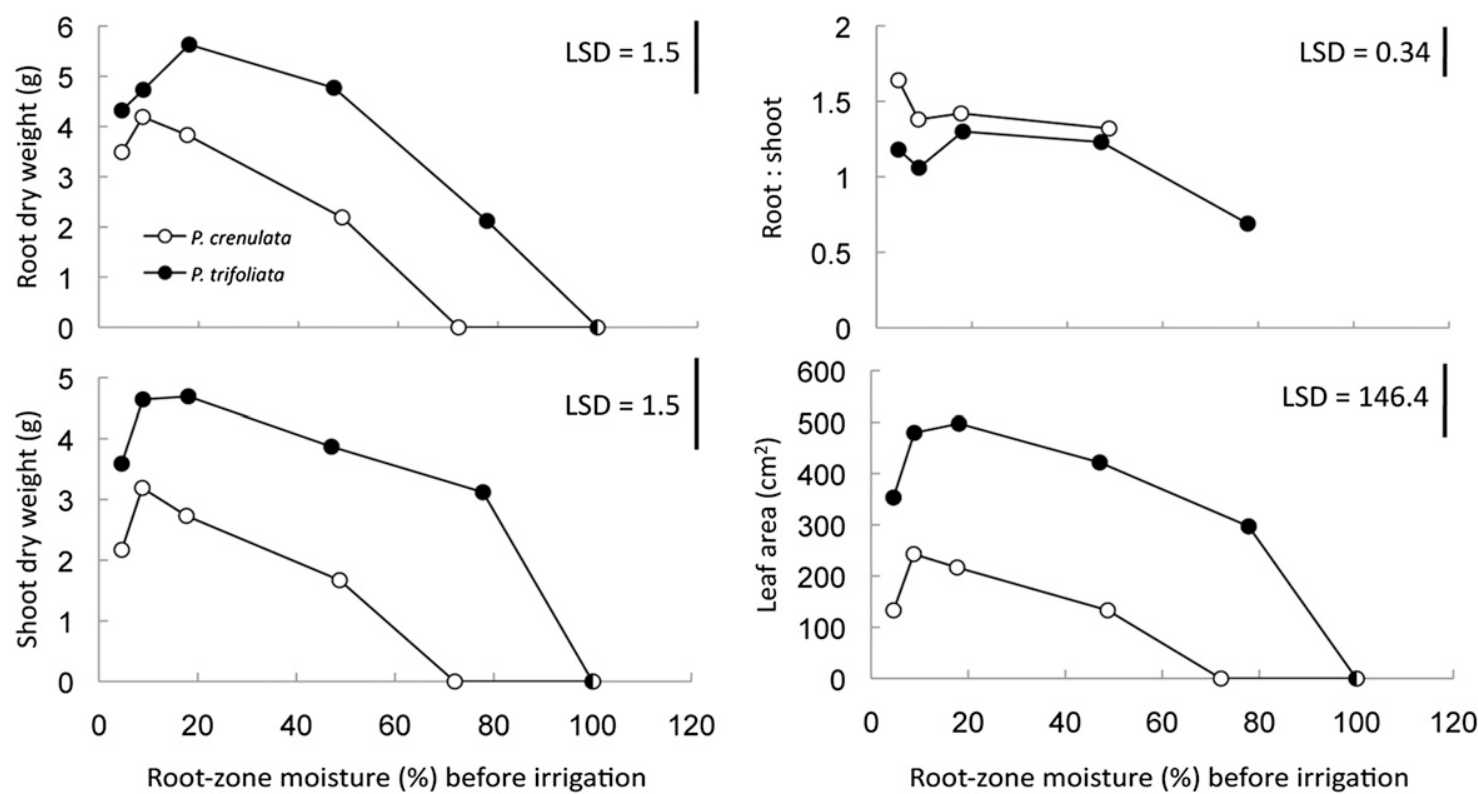

Fig. 4. Root dry weight, shoot dry weight, root:shoot, and total leaf area of seedlings of Ptelea grown for $38 \mathrm{~d}$ in each of six root-zone moisture conditions. Each circle represents the mean root-zone moisture at the time of irrigation and the mean response of four plants to treatments ranging from irrigation at $5 \%$ rootzone moisture by volume (left terminal) to complete inundation (right terminal). Values of zero are displayed for dry weights and leaf area when all plants of a taxon died from an inundation treatment. The right terminals for root:shoot represent plants subjected to shallow inundation $(P$. crenulata $)$ and moderate inundation $(P$. trifoliata) because root:shoot of dead plants is undefined.

that, although the taxon is found in habitats ranging from riparian terraces to drier chaparral, mortality from waterlogging of root zones was high in both greenhouse and field experiments (Richards and Chirman, 1994). This was not true of $S$. nigra ssp. canadensis, which not only tolerated complete inundation of root zones, but thrived under such conditions. Although the two genera were studied in separate experiments, precluding direct statistical comparison, Ptelea as a genus seems more susceptible to flooding than plants of Sambucus spp., because all plants of Ptelea died under complete inundation, and the western congener also died under partial inundation. Only Sambucus nigra ssp. canadensis represents a good choice for planting on sites characterized by saturation of root zones (Figs. 1 to 4). Our findings are consistent with previous studies demonstrating a similar relationship between the moisture availability of indigenous habitats of closely related taxa and tolerances of those taxa to root-zone flooding (Baraloto et al., 2007; Keeley, 1979).

Although growth of Sambucus from both regions was sensitive to drought, we found evidence that plants of the western taxon of Sambucus were more drought-adaptive than plants of the eastern congener. Plants of the western congener maintained higher rates of photosynthesis with drying of root zones and had greater root-to-shoot ratios under drought conditions, although plants of the eastern congener grew larger under all treatment conditions (Figs. 1 to 3). A reasonable interpretation is that Sambucus nigra ssp. cerulea may pay a physiological cost for the capacity to persist in a seasonally dry Mediterranean climate. Such a cost explains the greater root-to-shoot ratios and a greater capacity for photosynthesis under water deficit coupled with the lower
RGR and less accrual of biomass in roots and shoots under mesic conditions (Figs. 1 to 3 ). Despite the difference in rate of photosynthesis between congeners, specific leaf weight $\left(\mathrm{mg} \cdot \mathrm{mm}^{-2}\right)$ did not differ consistently between them (data not shown). The performance of this taxon across a range of root-zone moistures indicates that although S. nigra ssp. cerulea fixes carbon at a higher rate, even when subjected to repeated episodes of drought, it lacks the capacity of its eastern congener to alter its growth strategy to take advantage of abundant water. This interpretation is consistent with the results of previous research demonstrating a diminished plasticity of growth associated with drought resistance in woody taxa distributed along a soil-moisture gradient (Brenes-Arguedas et al., 2008).

Further evidence for drought adaptiveness in the western congener of Sambucus was the stable presence of pubescence on adaxial and abaxial leaf surfaces of plants in our common greenhouse environment regardless of rootzone moisture treatment. Although not quantified, we observed that the western congener of Sambucus had densely pubescent leaves, whereas leaves of the eastern congener were nearly glabrous. This pubescence, described by Corelli (2005) for S. nigra ssp. cerulea, may both increase the thickness of the leaf boundary layer and help prevent excess heat gain by reflecting solar radiation, thereby diminishing water loss through transpirational cooling and enabling photosynthesis for a greater period during the onset of drought (Sandquist and Ehleringer, 1998).

In contrast to our findings for Sambucus, there was no evidence that congeners of Ptelea differed fundamentally in responses to drying root zones (Figs. 1, 2, and 4). Just as plants of both congeners showed poor resistance to flooding, plants of both congeners likewise showed a similarly moderate resistance to drought. Habitat characteristics of the two congeners were not associated with strong differences in response to moisture stress. Other studies have shown that the woody taxa Alnus maritima (Marsh.) Muhl. ex Nutt., Pinckneya pubens Michx., Magnolia virginiana L., and Taxodium distichum (L.) Rich., all indigenous to bottomlands or waterlogged soils, have resistance to drought stress exceeding that expected based on moisture availability in their indigenous habitats (Nash and Graves, 1993; Schrader et al., 2005; Stewart et al., 2007). Ptelea trifoliata from eastern North America may likewise possess drought resistance greater than its native range would indicate and similar to that of $P$. crenulata from the Mediterranean climate of California. Although we did not measure the size of individual leaves, we observed the eastern Ptelea was characterized by leaves several times larger than those of the western congener. This difference has been noted in nature (Corelli, 2005), was stable in a common environment, and is likely adaptive in environments characterized by low soil moisture (Scoffoni et al., 2011).

Our findings provide new information about relative differences in response to root-zone water content between congeners of Sambucus and Ptelea, but additional evaluations with plants not restricted to containers are needed. The methods we used allowed for strict control over root-zone moisture and other components of the environment, but they precluded evaluation of potential stress-avoidance strategies. For example, Ackerly et al. (2002) found that 
S. nigra ssp. cerulea growing on a dry chaparral tended to have high predawn water potentials, which suggests these plants rely on a strategy of drought stress avoidance through deep rooting to endure such environments. Comparisons in landscape performance between the two congeners of each genus may help to elucidate the degree to which these eastern and western congeners differ in rooting depth. Although we did not find evidence for differences in response to drought between $P$. crenulata and $P$. trifoliata, we have observed that leaves of $P$. crenulata senesce during the dry season in their native habitat in California. This phenomenon, referred to as summer-deciduousness, is a strategy to minimize water loss that has been noted among other woody plants that, like $P$. crenulata, are not sclerophyllous (Ackerly et al., 2002; Nilsen and Muller, 1980). Because we did not observe leaf desiccation in response to our treatments, we may not have imposed the degree of moisture stress $P$. crenulata undergoes in its native habitats. Alternatively, our use of seedlings and additional environmental factors in nature such as temperature, vapor pressure deficit, and duration of root-zone moisture deficit might explain why leaves of mature $P$. crenulata in the wild desiccated during summer drought but leaves of young plants in the greenhouse did not. An experiment designed to investigate greater or extended drying of root zones as well as correlated environmental factors might reveal a superior drought-tolerance strategy for the western congener when soil moisture is extremely low.

We investigated responses of plants from two regions to drought and flooding, but we recognize there likely is substantial variation in physiological tolerances among many populations throughout the ranges of these genera. Both genera occur in several habitats in eastern North America, throughout the Southwest, and along the West Coast with populations in the Mediterranean climate of the San Francisco Bay area. Future work with these genera could focus on a comprehensive evaluation of provenance variation within and among species or subspecies with particular attention to sampling the variation that exists among habitats. For example, plants of
S. nigra ssp. cerulea in the San Francisco Bay area notably occupy habitats ranging from upper riparian terraces to seasonally dry chaparral, and it is not known to what extent sampling plants in these different habitats would reveal variation in physiological tolerances that could be of value to horticulturists.

\section{Literature Cited}

Abrams, M.D. 1990. Adaptations and responses to drought in Quercus species of North America. Tree Physiol. 7:227-238.

Abrams, M.D., M.E. Kubiske, and K.C. Steiner. 1990. Drought adaptations and responses in five genotypes of Fraxinus pennsylvanica Marsh. Photosynthesis, water relations and leaf morphology. Tree Physiol. 6:305-315.

Ackerly, D.D., C.A. Knight, S.B. Weiss, K. Barton, and K.P. Starmer. 2002. Leaf size, specific leaf area and microhabitat distribution of chaparral woody plants: Contrasting patterns in species level and community level analyses. Oecologia 130:449-457.

Bailey, V.L. 1962. Revision of the genus Ptelea (Rutaceae). Brittonia 14:1-45.

Baraloto, C., F. Morneau, D. Bonal, L. Blanc, and B. Ferry. 2007. Seasonal water stress tolerance and habitat associations within four neotropical tree genera. Ecology 88:478-489.

Bolli, R. 1994. Revision of the genus Sambucus. Diss. Bot. 223:1-227.

Brenes-Arguedas, T., M. Rios, G. Rivas-Torres, C. Blundo, P.D. Coley, and T.A. Kursar. 2008. The effect of soil on the growth performance of tropical species with contrasting distributions. Oikos 117:1453-1460.

Changnon, S.A. 2003. Temporal distribution of midwestern precipitation during the $20^{\text {th }} \mathrm{Cen}$ tury. Illinois State Water Survey Data/Case Study 2003-01, Champaign, IL.

Chunyang, L., F. Berninger, J. Koskela, and E. Sonninen. 2000. Drought responses of Eucalyptus microtheca provenances depend on seasonality of rainfall in their place of origin. Aust. J. Plant Physiol. 27:231-238.

Corelli, T. 2005. Illustrated field guide to the woody plants of the Santa Cruz Mountains. Monocot Press, Half Moon Bay, CA.

Dirr, M.A. 1998. Manual of woody landscape plants: Their identification, ornamental characteristics, culture, propagation, and uses. Stipes Publishing, Champaign, IL.

Eriksson, T. and M.J. Donoghue. 1997. Phylogenetic relationships of Sambucus and Adoxa (Adoxoideae, Adoxaceae) based on nuclear ribosomal ITS sequences and preliminary morphological data. Syst. Bot. 22:555-573.
Greene, E.L. 1906. The genus Ptelea in the western and southwestern United States and Mexico. Contr. U.S. Nat. Herb. 10:49-78.

Keeley, J.E. 1979. Population differentiation along a flood frequency gradient: Physiological adaptations to flooding in Nyssa sylvatica. Ecol. Monogr. 49:89-108.

Koch-Munz and Holyoak. 2008. An evaluation of the effects of soil characteristics on mitigation and restoration involving blue elderberry, Sambucus mexicana. Environ. Mgt. 42:49-65.

Kubiske, M.E. and M.D. Abrams. 1992. Photosynthesis, water relations, and leaf morphology of xeric versus mesic Quercus rubra ecotypes in central Pennsylvania in relation to moisture stress. Can. J. For. Res. 22:1402-1407.

Nash, L.J. and W.R. Graves. 1993. Drought and flood stress effects on plant development and leaf water relations of five taxa of trees native to bottomland habitats. J. Amer. Soc. Hort. Sci. 118:845-850.

NCDC. 2012. United States Dept. of Commerce. 1 Nov. 2012. <http://www.ncdc.noaa.gov>.

Nilsen, E.T. and W.H. Muller. 1980. An evaluation of summer deciduousness in Lotus scoparius Nutt. (T. \& G.). Amer. Midl. Nat. 103:88-95.

Parolin, P., C. Lucas, M.T.F. Piedade, and F. Wittmann. 2010. Drought responses of floodtolerant trees in Amazonian floodplains. Ann. Bot. (Lond.) 105:129-139.

Richards, J.H. and D.B. Chirman. 1994. Establishment of understory woody species of California Central Valley riparian habitats: Nutrient dynamics and flooding tolerance. UC Berkeley: University of California Water Resources Center, Berkeley, CA. 1 Nov. 2012. <http://escholarship. org/uc/item/1kk911jw>.

Sandquist, D.R. and J.R. Ehleringer. 1998. Intraspecific variation of drought adaptation in brittlebush: Leaf pubescence and timing of leaf loss vary with rainfall. Oecologia 113:162-169.

Schrader, J.A., S.J. Gardner, and W.R. Graves. 2005. Resistance to water stress of Alnus maritima: Intraspecific variation and comparisons to other alders. Environ. Exp. Bot. 53:281298.

Scoffoni, C., M. Rawls, A. McKown, H. Cochard, and L. Sack. 2011. Decline of leaf hydraulic conductance with dehydration: Relationship to leaf size and venation architecture. Plant Physiol. 156:832-843.

Stewart, J.R., R.D. Landes, A.K. Koeser, and A.L Pettay. 2007. Net photosynthesis and growth of three novel woody species under water stress: Calycanthus occidentalis, Fraxinus anomala, and Pinckneya pubens. HortScience 42:13411345 . 